\title{
The Public Health Impact of Legal Abortion: 30 Years Later
}

Before the Roe v. Wade decision in 1973, data on abortion in the United States were scarce. In 1955, experts had estimated, on the basis of qualitative assumptions, that 200,000-1,200,000 illegal abortions were performed each year. ${ }^{1}$ Despite its wide range, this estimate remained the most reliable indicator of the magnitude of induced abortion for many years. In 1967, researchers confirmed this estimate by extrapolating data from a randomized-response survey conducted in North Carolina: They concluded that a total of 800,000 induced (mostly illegal) abortions were performed nationally each year. ${ }^{2}$

At about this time, the availability of legally induced abortion in the United States gradually increased, starting in Mississippi in 1966 and then in Colorado the following year. The controversy that these developments would create spurred public health leaders to obtain accurate and complete information on the number and demographic characteristics of women obtaining abortions, as well as on the effects that legalization of abortion would have on morbidity and mortality. ${ }^{3}$ Three organizations-the Population Council, The Alan Guttmacher Institute and the Centers for Disease Control and Prevention (CDC)-collaborated to gather data by conducting what became known as abortion surveillance. Their combined effort was instrumental in the evaluation of the public health impact of the legalization of abortion.

\section{WOMEN OBTAINING ABORTIONS}

The initial surveillance effort documented the number and characteristics of women obtaining legally induced abortions. Between 1966 and 1969, 11 states, including California, liberalized their abortion laws. ${ }^{4}$ However, these changes had only a minimal impact on the reported number of legal abortions: Fewer than 25,000 legal abortions were reported to the CDC in 1969. ${ }^{5}$ Following the legalization of abortion in New York State in 1970 and in several other states between 1970 and 1973, the annual number of legally induced abortions rose dramatically, especially in New York City and California. For example, 586,760 legal abortions were performed in 1972-more than 20 times the number reported three years earlier. ${ }^{6}$

In deciding Roe v. Wade in January 1973, the U.S. Supreme Court ruled that restrictive state abortion laws were unconstitutional, thereby legalizing induced abortion throughout the country. As a result, the number of legal abortions increased to almost 1.6 million in 1980 (Figure 1, page 26) and continued at this level until the 1990s. ${ }^{7}$ Furthermore, in the few years after Roe $v$. Wade, the estimated number of illegal abortions gradually decreased. Thus, the initial increase in the number of legal abortions was likely due to the declining demand for illegal abortion services as legal abortion became available. ${ }^{8}$ The decline also explained why Roe v. Wade's public health impact (i.e., in reducing morbidity and mortality) far exceeded its demographic effect (i.e., in reducing the number of births).

The characteristics of women obtaining legal abortions changed greatly in response to Roe v. Wade (Table 1). ${ }^{9}$ The proportion of women having abortions who were nonwhite increased between 1972 and 1999 (from 23\% to 44\%), as did the proportion who were unmarried (from $70 \%$ to $81 \%$ ). By enabling unmarried women of racial minorities to safely terminate unintended pregnancies, Roe v. Wade disproportionately benefited them. In addition, the increased accessibility of legal abortion services after 1973 allowed women to obtain abortions closer to home: More than $90 \%$ of legal abortions occurred in the woman's home state in 1980-1999, compared with 56\% in 1972. Therefore, legalization also lowered costs for women. ${ }^{10}$ Furthermore, as baby boomers aged, the proportion of women obtaining legal abortions who were older than 24 increased during

\begin{tabular}{|c|c|c|c|c|}
\hline Characteristic & $\begin{array}{l}1972 \\
(\mathrm{~N}= \\
586,760)\end{array}$ & $\begin{array}{l}1980 \\
(\mathrm{~N}= \\
1,297,606)\end{array}$ & $\begin{array}{l}1990 \\
(\mathrm{~N}= \\
1,429,577)\end{array}$ & $\begin{array}{l}1999 \\
(\mathrm{~N}= \\
861,789)^{*}\end{array}$ \\
\hline \multicolumn{5}{|l|}{ Race } \\
\hline White & 77.0 & 69.9 & 64.8 & 56.2 \\
\hline Nonwhite & 23.0 & 30.1 & 35.2 & 43.8 \\
\hline \multicolumn{5}{|l|}{ Marital status } \\
\hline Married & 29.7 & 23.1 & 21.7 & 19.2 \\
\hline Unmarried & 70.3 & 76.9 & 78.3 & 80.8 \\
\hline \multicolumn{5}{|c|}{ State where abortion occurred } \\
\hline \multicolumn{5}{|c|}{ Woman's home } \\
\hline state & 56.2 & 92.6 & 91.8 & 91.2 \\
\hline Another state & 43.8 & 7.4 & 8.2 & 8.8 \\
\hline \multicolumn{5}{|l|}{ Age } \\
\hline$\leq 19$ & 32.6 & 29.2 & 22.4 & 19.2 \\
\hline $20-24$ & 32.5 & 35.5 & 33.2 & 32.2 \\
\hline$\geq 25$ & 34.9 & 35.3 & 44.4 & 48.6 \\
\hline \multicolumn{5}{|c|}{ Weeks of gestation } \\
\hline$\leq 8$ & 34.0 & 51.7 & 51.6 & 57.6 \\
\hline $9-10$ & 30.7 & 26.2 & 25.3 & 20.2 \\
\hline $11-12$ & 17.5 & 12.3 & 11.7 & 10.2 \\
\hline $13-15$ & 8.4 & 5.1 & 6.4 & 6.2 \\
\hline $16-20$ & 8.2 & 3.9 & 4.0 & 4.3 \\
\hline$\geq 21$ & 1.3 & 0.9 & 1.0 & 1.5 \\
\hline Total & 100.0 & 100.0 & 100.0 & 100.0 \\
\hline
\end{tabular}

By Willard Cates, Jr., David A. Grimes and Kenneth F. Schulz

Willard Cates, Jr., is adjunct professor, David A. Grimes is professor and Kenneth F. Schulz is adjunct professor, all at the Department of Obstetrics and Gynecology, School of Medicine, University of North Carolina, Chapel Hill, NC. 


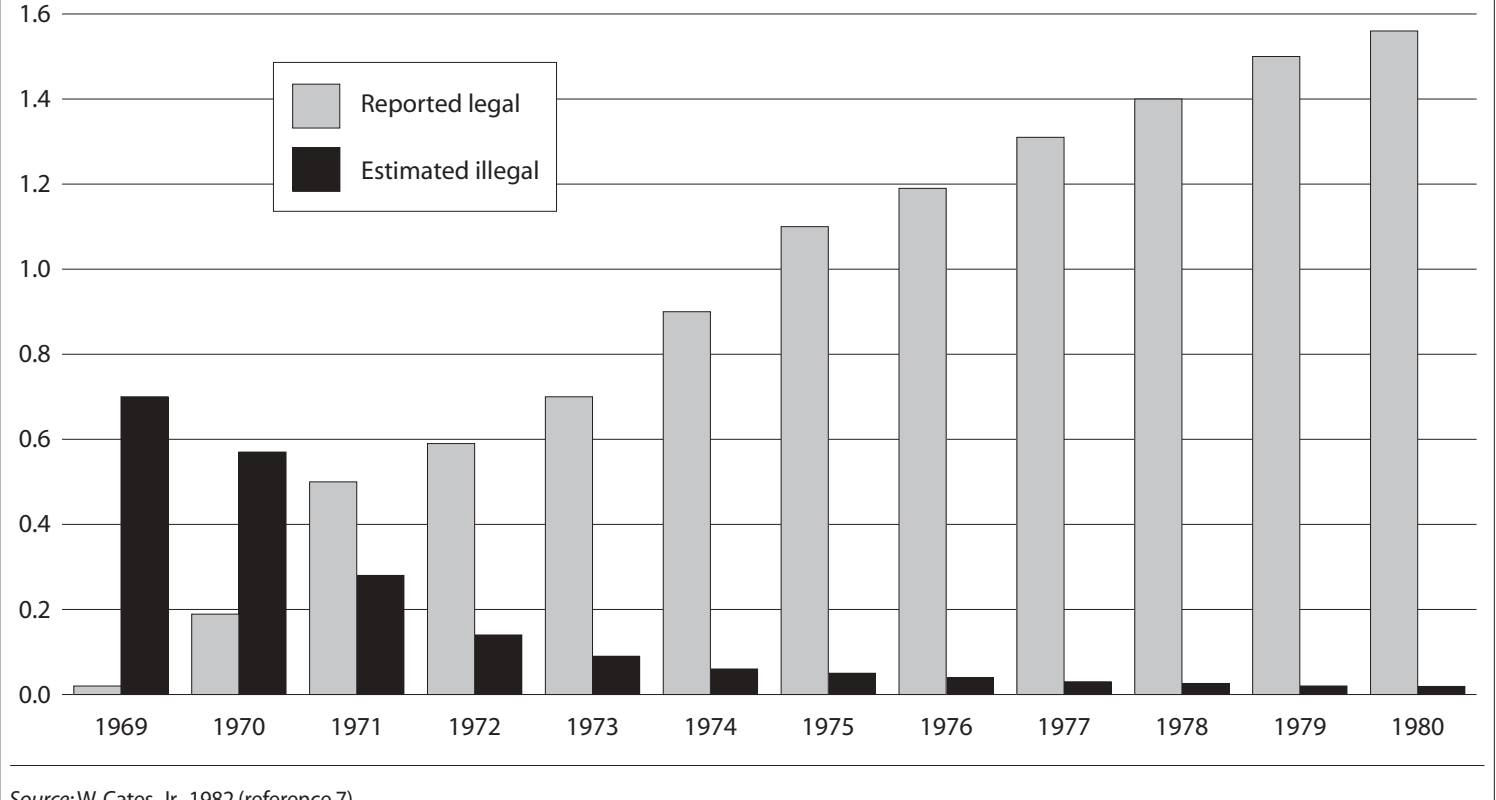

Source:W. Cates, Jr., 1982 (reference 7).

1972-1999, from 35\% to $49 \%$. $^{11}$

The legalization of abortion also led to changes in when women sought abortions: In 1970, nearly one in four abortions were performed at 13 weeks' gestation or later, ${ }^{12}$ compared with one in 10 a decade later (Table 1 ). In addition, more than half of women obtaining abortions after 1980 did so at eight weeks' gestation or earlier. Obtaining abortions earlier in the pregnancy makes the procedure safer, because earlier abortion is associated with a reduced risk of complications. ${ }^{13}$ As medically induced abortions become more common, ${ }^{14}$ abortions are likely to be performed at even earlier gestational ages.

In addition to monitoring the characteristics of women obtaining legal abortions, the national surveillance systems examined the types of procedures performed and service locations. Most abortions in 1973 were performed in hospitals. Today, most are performed in nonhospital facilities (the so-called freestanding clinics) and a minority take place in physicians' offices. ${ }^{15}$ The initiation of abortion services at many freestanding clinics in the 1980s was soon accompanied by the delivery of other reproductive health services, ${ }^{16}$ such as family planning and contraceptive counseling, routine outpatient gynecologic care, male and female sterilization, and infertility testing. By performing outpatient surgical procedures safely and economically, these facilities set a precedent for other specialties-from podiatry to ophthalmology-to perform what have become routine outpatient procedures.

\section{ABORTION MORBIDITY AND MORTALITY}

The replacement of unsafe, illegal abortions by safer, legal procedures meant that women experienced fewer serious complications. Studies performed at the national, state and local levels revealed that hospitalization of women with complications from illegal abortion decreased gradually after Roe v. Wade. ${ }^{17}$ Estimates from the National Hospital Discharge Survey between 1970 and 1977 also demonstrated a general decline in the number of women treated for complications of illegal abortions; a disproportionate decrease occurred in the year of Roe $v$. Wade. ${ }^{18}$ Moreover, reports from individual hospitals on the East and West Coasts documented similar declines in abortion complications. ${ }^{19}$

Roe v. Wade also stimulated research into how to perform legal abortions even more safely. The main vehicle for assessing the outcomes of different abortion procedures was a multicenter cohort study-the Joint Program for the Study of Abortion (JPSA) ${ }^{20}$-which the Population Council began in 1970 and the CDC continued in 1971. Over seven years, the CDC collected detailed clinical data on more than 160,000 abortions induced legally through a variety of procedures in more than 30 U.S. institutions.

The study represented an early effort to practice evidencebased medicine, and its findings transformed the way in which legal abortions were performed in the 1970s. The researchers concluded that use of vacuum aspiration to terminate first-trimester pregnancies was faster and safer than dilation and sharp curettage, which was until then conventionally used to perform first-trimester abortion and to treat incomplete abortions. ${ }^{21}$ Consequently, suction curettage replaced sharp curettage as the main method of abortion: In 1970, suction and sharp curettage accounted for $54 \%$ and $46 \%$ of abortions, respectively; 22 by 1998 , suction curettage was used for nearly all abortions (96\%). ${ }^{23}$

The JPSA findings also showed that dilation and evacuation (D\&E) was safer than intra-amniotic instillation of abortifacients to induce abortion at 13 weeks' gestation or 
later; ${ }^{24}$ hence, the strict concept of "trimester threshold" that underlay the Roe $v$. Wade decision became irrelevant. ${ }^{25 *}$ After Roe $v$. Wade, JPSA concluded that surgical evacuation was the safest method of abortion after 12 weeks' gestation. The proportion of second-trimester abortions that were performed by D\&E subsequently rose, to more than $90 \%$ by the 1990 s. ${ }^{26} \mathrm{D} \& \mathrm{E}$ not only has made abortion safer, but also has lowered costs, minimized inconvenience and made second-trimester abortion less traumatic emotionally for women.

According to JPSA, physicians' skills also improved during the 1970s. Before Roev. Wade, abortion methods were generally not included in obstetrics and gynecology training. ${ }^{27}$ Gynecology residents typically encountered uterine evacuation only when performing sharp curettage on a nonpregnant woman for diagnostic purposes or when removing tissue after a spontaneous abortion. Even then, surgical techniques used in these two situations differed from those used in induced abortion. Roe v. Wade allowed physicians to learn not only the appropriate methods, but also how to manage associated complications. Improved training was one factor that helped to reduce abortion-related morbidity and mortality in the first decade of legal abortion. Other factors included development of more effective methods of local and general anesthesia, use of osmotic methods of cervical dilation such as laminaria tents (seaweed sticks), physicians' greater willingness to reevacuate a uterus that might not be empty and abandonment of hysterotomy for abortion.

As the availability of legally induced abortion increased, mortality due to abortion dropped sharply: The number of abortion-related deaths per million live births fell from nearly 40 in 1970 to eight in $1976 .{ }^{28}$ The trend was caused mainly by a decline in the absolute number of deaths from illegal abortion-especially after Roe v. Wade-from 39 in 1972 to two in $1976 .{ }^{29}$ After 1975 , mortality due to legally induced abortion also fell-from more than three deaths per 100,000 abortions in 1975 to about one in 1976 and even fewer thereafter. ${ }^{30}$

The main reason for the reductions in both morbidity and mortality is that legally induced abortion is markedly safer than illegally induced abortion. Moreover, legal abortion is safer than the third choice available to pregnant women-continuing a pregnancy to term. ${ }^{31}$ For example, in $2000,23 \%$ of births were abdominal (cesarean) deliveries, whereas fewer than $1 \%$ of suction curettage procedures required intra-abdominal surgery. ${ }^{32}$ Therefore, a woman carrying a pregnancy to term has several hundred

*The Supreme Court used the pregnancy trimester concept as the basis for Roe v. Wade: Because early induced abortion was much safer than a continued pregnancy, the Court recognized the right of a woman and her physician to choose to terminate a pregnancy during the first trimester, independent of any statutory limitations. However, curettage procedures were considered too dangerous for the woman after the first trimester. In Doe v. Bolton, the companion decision to Roe v. Wade, the Court ruled that although the state could not prohibit a woman from choosing to terminate a pregnancy in the second trimester, it could, for health reasons, regulate the conditions under which the abortion was performed (source: reference 25). times the risk of requiring major surgery of a woman undergoing suction abortion. Furthermore, in the 1970s, the risk of death related to induced abortion at 16 weeks' gestation or earlier was one-seventh that related to pregnancy and childbirth, even after adjustment for study year, age and race. ${ }^{33}$ Today, legal abortion is less likely than an injection of penicillin to cause death.

\section{CONCLUSION}

Roe v. Wade transformed abortion from an unsafe, clandestine procedure to one performed under safe, medical conditions. The 1970s thus saw a reduction in abortionrelated complications and deaths as safer options became available to American women choosing to terminate an unplanned pregnancy. Since Roe $v$. Wade, a full generation of Americans have come to expect abortion services to be available alongside other health services.

However, the topic of abortion remains one of the most controversial areas of public policy. The intense public debate has allowed us to know more about legally induced abortion than about any other procedure. Although the available medical evidence does not directly address society's moral issues, it allows an objective insight to the health effects of wider access to legal abortion. Despite polarized opposition to the choice of legal abortion, the public health data have helped guide judicial rulings, legislative actions and surgeon general's reports, which have together allowed safer choices for American women of reproductive age.

\section{REFERENCES}

1. Calderone MS, Abortion in the United States, New York: Paul B. Hoeber, 1958, pp. 178-180

2. Abernathy JR, Greenberg BG and Horvitz DG, Estimates of induced abortion in urban North Carolina, Demography, 1970, 7(1):19-29.

3. Smith JC and Cates W, Jr., The public health need for abortion statistics, Public Health Reports, 1978, 93(2):194-197.

4. Centers for Disease Control (CDC), Abortion Surveillance, Annual Summary, 1969, Atlanta: CDC, 1970.

5. Ibid.

6. CDC, Abortion Surveillance, 1975, Atlanta: CDC, 1977.

7. Cates W, Jr., Legal abortion: the public health record, Science, 1982, 215(4540):1586-1590; and Finer LB and Henshaw SK, Abortion incidence and services in the United States in 2000, Perspectives on Sexual and Reproductive Health, 2003, 35(1):6-15.

8. Council on Scientific Affairs, American Medical Association, Induced termination of pregnancy before and after Roe $v$. Wade: trends in the mortality and morbidity of women, Journal of the American Medical Association, 1992, 268(22):3231-3239.

9. CDC, 1977, op. cit. (see reference 6).

10. Cates W, Jr., et al., The effect of delay and choice of method on the risk of abortion morbidity, Family Planning Perspectives, 1977, 9(6):266-273.

11. Elam-Evans LD et al., Abortion surveillance-United States, 1999, Morbidity and Mortality Weekly Report, 2002, 51(5509):1-28; and Jones RK, Darroch JE and Henshaw SK, Patterns in the socioeconomic characteristics of women obtaining abortions in 2000-2001, Perspectives on Sexual and Reproductive Health, 2002, 34(5):226-235.

12. CDC, 1977 , op. cit. (see reference 6).

13. Cates W, Jr., et al., 1977, op. cit. (see reference 10). 
14. Grimes DA, Medical abortion in early pregnancy: a review of the evidence, Obstetrics \& Gynecology, 1997, 89(5):790-796.

15. Finer LB and Henshaw SK, 2003, op. cit. (see reference 7).

16. Henshaw SK, The accessibility of abortion services in the United States, Family Planning Perspectives, 1991, 23(6):246-252 \& 263.

17. Cates W, Jr., 1982, op. cit. (see reference 7).

18. Bracken MB, Freeman DH, Jr., and Hellenbrand K, Hospitalization for medical-legal and other abortions in the United States 1970-1977, American Journal of Public Health, 1982, 72(1):30-37.

19. Goldstein P and Stewart G, Trends in therapeutic abortion in San Francisco, American Journal of Public Health, 1972, 62(5):695-699; Lanham JT, Kohl SG and Bedell JH, Changes in pregnancy outcome after liberalization of the New York State abortion law, American Journal of Obstetrics and Gynecology, 1974, 118(4):485-492; Kahan, RS, Baker LD and Freeman MG, The effect of legalized abortion on morbidity resulting from criminal abortion, American Journal of Obstetrics and Gynecology, 1975, 121(1):114-116; Stewart GK and Goldstein PJ, Therapeutic abortion in California: effects of septic abortion and maternal mortality, $\mathrm{Ob}$ stetrics \& Gynecology, 1971, 37(4):510-514; Glass L et al., Effects of legalized abortion on neonatal mortality and obstetrical morbidity at Harlem Hospital Center, American Journal of Public Health, 1974, 64(7):717-718; Seward PN, Ballard CA and Ulene AL, The effect of legal abortion on the rate of septic abortion at a large county hospital, American Journal of Obstetrics and Gynecology, 1973, 115(3):335-338; and The Alan Guttmacher Institute (AGI), Safe and Legal: 10 Years' Experience with Legal Abortion in New York State, New York: AGI, 1980, p. 23.

20. Cates W, Jr., et al., 1977, op. cit. (see reference 10).

21. Ibid.

22. CDC, 1977 , op. cit. (see reference 6).

23. Elam-Evans LD et al., 2002, op. cit. (see reference 11).

24. Grimes DA et al., Midtrimester abortion by dilatation and evacuation: a safe and practical alternative, New England Journal of Medicine,
1977, 296(20):1141-1145

25. Cates W, Jr., Grimes DA and Hogue LL, Justice Blackmun and legal abortion-a besieged legacy to women's reproductive health, American Journal of Public Health, 1995, 85(9):1204-1206.

26. Elam-Evans LD et al., 2002, op. cit. (see reference 11).

27. Burkman RT et al., University abortion programs: one year later, American Journal of Obstetrics and Gynecology, 1974, 119(1):131-136.

28. Cates W, Jr., et al., Legalized abortion: effect on national trends of maternal and abortion-related mortality (1940-1976), American Journal of Obstetrics and Gynecology, 1978, 132(2):221-224.

29. Lawson HW et al., Abortion mortality, United States, 1972 through 1987, American Journal of Obstetrics and Gynecology, 1994, 171(5): 1365-1372.

30. Ibid.; and Elam-Evans LD et al., 2002, op. cit. (see reference 11).

31. LeBolt SA, Grimes DA and Cates W, Jr., Mortality from abortion and childbirth: are the populations comparable? Journal of the American Medical Association, 1982, 248(2):188-191.

32. Martin JA et al., Births: final data for 2000, National Vital Statistics Report, 2002, 50(5):14-15.

33. LeBolt SA, Grimes DA and Cates W, Jr., 1982, op. cit. (see reference 31).

\section{Acknowledgment}

This article is adapted, by permission of Elsevier Science, from Cates W, Jr., Grimes DA and Schulz KF, Abortion surveillance at CDC: creating public health light out of political heat, American Journal of Preventive Medicine, 2000, 19(1S):12-17, (c) 2000, American Journal of Preventive Medicine.

Author contact: wcates@fhi.org

\section{Acknowledgment to Reviewers}

The editors wish to express their appreciation to the following reviewers for their assistance in evaluating material for Perspectives on Sexual and Reproductive Health in 2002:

\author{
Joyce C. Abma \\ John E. Anderson \\ Bruce J. Armstrong \\ Christine A. Bachrach \\ Anne C. Beal \\ David L. Bell \\ John O. G. Billy \\ Claire D. Brindis \\ Larry L. Bumpass \\ Martha Campbell \\ Anjani Chandra \\ Sylvia M. Clark \\ Deborah A. Cohen \\ Norman Constantine \\ Ralph J. DiClemente \\ Patricia M. Dietz \\ Patricia J. Dittus \\ Rosalie Dominik \\ Patricia L. East \\ Jonathan E. Ellen \\ Abigail English
}

\author{
Lorraine E. Ferris \\ Lawrence B. Finer \\ Julianna S. Gonen \\ William R. Grady \\ Clara S. Haignere \\ Cynthia Harper \\ S. Marie Harvey \\ Wendy L. Hellerstedt \\ Roberta Herceg-Baron \\ Dennis Hogan \\ Carol J. Rowland Hogue \\ Robert A. Hummer \\ Larry D. Icard \\ Pamela Jo Johnson \\ Robert Kaestner \\ Jeffrey A. Kelly \\ Lorraine V. Klerman \\ Lori Kowaleski-Jones \\ Eva S. Lefkowitz \\ David J. Landry \\ Leslie Tarr Laurie
}

Evelyn Lehrer
Phillip B. Levine
Lisa Lieberman
Rebecka Lundgren
Andrea MacKay
Steven P. Martin
Rebecca A. Maynard
Mignon R. Moore
Kelly A. Musick
Lydia O'Donnell
Laura L. Otto-Salaj
Angela Papillo
Marian R. Passannante
Nadine Peacock
Ruth Petersen
Susan Philliber
Virginia H. Poole
Suzanne T. Poppema
Ellen Rautenberg
Marjorie R. Sable
Héctor Sánchez-Flores

John S. Santelli

Peter Shin

David F. Sly

Freya L. Sonenstein

John Stanback

Joseph B. Stanford

Markus Steiner

Elizabeth Hervey Stephen

Geoffrey R. Swain

Megan Sweeney

Jeanne M. Tschann

Barbara VanOss Marín

Sally Ward

David Lee Warner

Lance S.Weinhardt

Paul Whittaker

Constance M. Wiemann

Deborah Schild Wilkinson

Susan N.Wilson

Jane G. Zapka 